\title{
Assessment of Diabetes Related Knowledge, Attitude and Practice among Diabetics and Non-diabetics using Self Prepared Questionnaire for Awareness of Health Promotion
}

\author{
Sridhar Srimath Tirumala Konduru, Amit Ranjan, Karthik, Sravanthi Muddada, Shabnam Shaik, \\ Lakshmi Sowjanya Vakkapatla
}

Department of Pharmacy Practice, Shri Vishnu College of Pharmacy, Bhimavaram, Andhra Pradesh, INDIA.

\begin{abstract}
Introduction: As diabetes mellitus is one of the most challenging public health problem in 21 st century, it is important to know about the awareness level of a disease condition in a population, which plays a vital role in future development, early detection and prevention of disease. Objective: To assess the awareness and knowledge regarding diabetes mellitus among diabetic and non-diabetic subjects. Methods: A prospective and observational study was done in 100 diabetic and 50 non-diabetic subjects. All in- patients and out- patients either gender, of age 20-80 years were included in the study. Paediatric patients, pregnant/lactating women were excluded. Result: After analysing the scores, it was found that among diabetic patients $46 \%$ had poor knowledge, $45 \%$ had medium knowledge and $9 \%$ had good knowledge regarding Diabetes Mellitus where as $64 \%$ of non-diabetics had poor knowledge, 34\% of non-diabetics had medium knowledge and $2 \%$ of non-diabetics had good knowledge regarding Diabetes Mellitus. Conclusion: Overall, our study concludes that diabetic patients had more knowledge regarding diabetes mellitus than non-diabetic subjects.
\end{abstract}

Key words: Awareness, Diabetes mellitus, knowledge, Early detection, Prevention, Complications.

\section{INTRODUCTION}

As Diabetes Mellitus (DM) is one of the most challenging public health problems in $21^{\text {st }}$ century. It currently affects over 366 million people worldwide and this figure is likely to double by 2030. It is important to know about the awareness level of a disease condition in a population, which plays a vital role in future development, early detection and prevention of disease. Prevention is important because the burden of the diabetes and its complications on health care and its economic implications are enormous, especially for a developing country like India. Patient education is always considered an essential element of DM management. Studies have consistently shown that improved glycaemic control and strict metabolic control can delay or prevent the progression of complications associated with diabetes. Evidences sug- gest that patients, who are knowledgeable about DM self-care, have better long term glycaemic control. Thus it is indispensable to ensure that patient's knowledge, attitudes and practices are adequate.

\section{Risk factors}

Awareness of risk factors is a prerequisite to prevent diabetes among general population and also in high-risk groups, such as Impaired Fasting Glucose (IFG) and Impaired Glucose Tolerance (IGT). The common risk factors are obesity, family history, insulin resistance, hypertension, and hyperlipidemia.

\section{Complications}

Major problem with diabetes is that if it is poorly controlled it leads to increase in micro vascular and macro vascular complications such as coronary artery disease,
DOI: 10.5530ijopp.10.1.8

Address for correspondence: Dr. Sridhar Srimath Tirumala Konduru,

Department of Pharmacy Practice, Shri Vishnu College of pharmacy, Bhimavaram, Andhra Pradesh, INDIA.

Phone no: 9642880200

E-mail: sridharstk@gmail.com

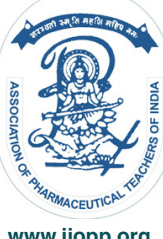

www.ijopp.org 
stroke, blindness, kidney failure, foot amputation, poor blood supply to the limbs leading to increased morbidity. Patient education becomes a central component in the prevention and control of disease.

\section{Self-care practices}

The self-care practices of individuals are influenced by their knowledge about diabetes; the more they know about their illness, more they would have self-management skills. Many research work published have shown that the diabetic population don't have enough awareness of diabetes, the proper use of medications, life style modifications, dietary plans, myths associated with insulin and other education programs on health issue.

\section{METHODOLOGY}

\section{Study Design}

The study was a Prospective and Observational study.

\section{Study Site}

This study was conducted at Bhimavaram Hospital, Bhimavaram. It is a 300 bedded multi-speciality tertiary care hospital.

\section{Study Period}

The study was carried out over a period of six months from Dec 2015 to May 2016.

\section{Source Of Data And Materials}

- Method of collection of data:

- Patient interview

- Patient case note/prescription

- Patient counselling

- Method of collection of material

- Self-questionnaire

- Patient consent form

- Patient data collection form

- Diet chart

- Chart on insulin administration technique.

\section{Study Criteria}

\section{Suggested Inclusion Criteria}

- Male and female Diabetic and Non-diabetic population between 20 to 80 years old.

- Patients with type1 and type 2 diabetes.

\section{Exclusion Criteria:}

- Paediatric Patients.

- Patients who are not willing to give the consent form.

- Pregnant/lactating women.

\section{Study Procedure:}

\section{Method of data collection}

A total of 150 subjects were interviewed and their details were noted in a specially designed data collection form. Among them 100 subjects were diabetic and 50 were non-diabetic. The data collection form contains information about socio demographic characteristics, questionnaire about patient awareness on illness, risk factor, symptoms, complications, self-care practices, life style modifications and management. The awareness was assessed by giving scores based on the answers given by the participants during the interview. The questionnaires were interpreted into local languages, to those who could not understand or read English.

\section{Research and Ethical Committee Aproval}

Institutional research and ethical committee approved the study and issued a letter of permission to conduct the study.

\section{Statistical Methods}

Descriptive statistical analysis has been carried out in the present study. Mean + Standard deviation (Min-max), one way ANOVA and $\mathrm{p}$ value as well as Percentages

\section{RESULTS AND DISCUSSION}

The chronic hyperglycemia of diabetes is associated with long-term damage, dysfunction, and failure of various organs, especially the eyes, kidneys, nerves, heart, and blood vessels.

This study was conducted to improve the knowledge regarding disease characteristics, natural course, complications and management of diabetes mellitus. The study was conducted for 6 months from December 2015 to May 2016 in a tertiary care hospital. A total of 150 participants were selected in the study of which 100 are diabetic patients and 50 were non-diabetic subjects.

Table 1 shows demographic characteristics of participants. Most of the patients were in the age group of $41-59$ yrs and the lowest age group was 20-40 yrs. Diabetic patients which include $64(64 \%)$ men, $36(36 \%)$ women and non-diabetic patients include $21(42 \%)$ men, $29(58 \%)$ women. The mean and standard deviation of diabetic and non-diabetic patients regarding gender was $50 \pm 19.8$ and $46 \pm 5.65$. In our study knowledge regarding diabetes mellitus was increase in graduates which was consistent with the study done by (Nehad M. Hamoudi et al 2012). The mean and standard deviation of educational status of diabetic patients was $19.8 \pm 5.44$ and non-diabetic subjects were $39.6 \pm$ 
Table 1: Socio demographic profile of diabetic and non-diabetic subjects

\begin{tabular}{|c|c|c|c|c|}
\hline Parameters & $\begin{array}{l}\text { Diabetic } \\
\text { patients } \\
(n=100)\end{array}$ & $\begin{array}{c}\% \\
\text { Diabetic } \\
\text { patients }\end{array}$ & $\begin{array}{c}\text { Non-diabetic } \\
\text { patients } \\
(n=50)\end{array}$ & $\begin{array}{l}\% \text { Non- } \\
\text { diabetic } \\
\text { patients }\end{array}$ \\
\hline \multicolumn{5}{|c|}{ GENDER } \\
\hline Male & 64 & 64 & 21 & 42 \\
\hline Female & 36 & 36 & 29 & 58 \\
\hline \multicolumn{5}{|c|}{ BMI } \\
\hline $\begin{array}{l}\text { Under } \\
\text { Weight }\end{array}$ & 2 & & 1 & \\
\hline Normal & 34 & & 18 & \\
\hline Over Weight & 52 & & 28 & \\
\hline $\begin{array}{l}\text { Obese } \\
\text { class I }\end{array}$ & 11 & & 1 & \\
\hline $\begin{array}{l}\text { Obese } \\
\text { class II }\end{array}$ & 1 & & 2 & \\
\hline \multicolumn{5}{|c|}{ Family History } \\
\hline Yes & 36 & 36 & 14 & 28 \\
\hline No & 64 & 64 & 36 & 72 \\
\hline \multicolumn{5}{|c|}{ DURATION OF ILLNESS } \\
\hline $0-1 y r$ & 27 & 27 & & \\
\hline $1-5 y r$ & 31 & 31 & & \\
\hline$>5 y r$ & 42 & 42 & & \\
\hline
\end{tabular}

Table 2: Educational status of the study population

\begin{tabular}{ccccc}
\hline Education & $\begin{array}{c}\text { Diabetic } \\
\text { Patients }\end{array}$ & $\begin{array}{c}\% \\
\text { Diabetic } \\
\text { Patients }\end{array}$ & $\begin{array}{c}\text { Non- } \\
\text { diabetic } \\
\text { Patients }\end{array}$ & $\begin{array}{c}\% \text { Non- } \\
\text { diabetic } \\
\text { Patients }\end{array}$ \\
\hline $\begin{array}{c}\text { Primary } \\
\text { Schooling }\end{array}$ & 28 & 28 & 10 & 20 \\
$\begin{array}{c}\text { Secondary } \\
\text { Schooling }\end{array}$ & 15 & 15 & 5 & 10 \\
$\begin{array}{c}\text { Graduate } \\
\text { Post }\end{array}$ & 22 & 22 & 13 & 26 \\
$\begin{array}{c}\text { Graduate } \\
\text { Illiterate }\end{array}$ & 15 & 15 & 9 & 18 \\
Mean & 19 & 19 & 13 & 26 \\
Standard & 5.4497 & & 3.3166 & \\
Deviation & & & & \\
\hline
\end{tabular}

10.8. $36 \%$ diabetic and $14 \%$ non-diabetic patients had family history of diabetes where as $64 \%$ diabetic and $72 \%$ non-diabetic had no family history of diabetes. The mean and standard deviation for family history of diabetic patients was $50 \pm 19.8$ while in non-diabetic patients $50 \pm 31.1$. Most of the responders had duration of disease $>5$ yrs where as $27 \%$ of people were having duration of disease $<1 \mathrm{yr}$. Mean and standard deviation of their duration of illness was $33 \pm 7.77$. Majority of the diabetic and non-diabetic subjects are overweight and their mean and standard deviation were $20 \pm 22.29$, $10 \pm 12.38$.
Table 3: Percentage of diabetic and non-diabetic patients on knowledge on risk factors

\begin{tabular}{ccccc} 
Risk factors & $\begin{array}{c}\text { Diabetic } \\
\text { Patients }\end{array}$ & $\begin{array}{c}\% \\
\text { Diabetic }\end{array}$ & $\begin{array}{c}\text { Non- } \\
\text { diabetic } \\
\text { patients }\end{array}$ & $\begin{array}{c}\% \text { Non- } \\
\text { diabetic } \\
\text { patients }\end{array}$ \\
\hline Patients & & & & \\
Obesity & 45 & 45 & 24 & 48 \\
Family History & 63 & 63 & 39 & 78 \\
Hypertension & 19 & 18 & 20 & 40 \\
Lack Of Physical & 27 & 27 & 12 & 24 \\
Activity & & & & \\
Smoking & 19 & 19 & 14 & 28 \\
GDM & 3 & 3 & 6 & 12 \\
Others & 2 & 2 & 5 & 10 \\
All & 2 & 2 & 0 & 0 \\
None & 28 & 28 & 4 & 8
\end{tabular}

Table 4: Gender wise knowledge on diabetes among diabetic patients

\begin{tabular}{ccc}
\hline Parameters & $\begin{array}{c}\text { \%Diabetic male } \\
\text { patients }\end{array}$ & $\begin{array}{c}\% \text { Diabetic female } \\
\text { patients }\end{array}$ \\
\hline Risk factors & $51 \%$ & $26 \%$ \\
Symptoms & $61 \%$ & $35 \%$ \\
Complications & $54 \%$ & $26 \%$
\end{tabular}

Table 5: Gender wise knowledge on diabetes among non-diabetic patients

\begin{tabular}{ccc}
\hline Parameters & $\begin{array}{c}\text { \% Non-diabetic male } \\
\text { Patients }\end{array}$ & $\begin{array}{c}\% \text { Non-diabetic } \\
\text { female Patients }\end{array}$ \\
\hline Risk factors & 42 & 52 \\
Symptoms & 42 & 52 \\
Complications & 32 & 50 \\
No & 6 & 9
\end{tabular}

\section{Knowledge regarding risk factors of diabetes mellitus}

Table 3 shows the knowledge regarding the risk factors of diabetes. $63 \%$ diabetic patients and $78 \%$ non-diabetic patients were having idea that hereditary is one of the major risk factor for diabetes mellitus. $48 \%$ diabetic and $45 \%$ non-diabetic were aware that obesity can cause diabetes mellitus. While coming to other risk factors $19 \%$ diabetic and $40 \%$ non-diabetic, $27 \%$ diabetic and $24 \%$ non-diabetic have the awareness on hypertension and lack of physical activity. Smoking also one cause and it was found to be aware in 19\% diabetic and $28 \%$ non-diabetic subjects.In the present study $28 \%$ diabetic patients and $8 \%$ non-diabetic patients was found to be not aware of any risk factor of diabetes. Mean and standard deviation of diabetic and non-diabetic patients regarding risk factors was found to be $23.1 \pm 20.73,27.5$ \pm 24.5 .

Indian Journal of Pharmacy Practice, Vol 10, Issue 1, Jan-Mar, 2017 


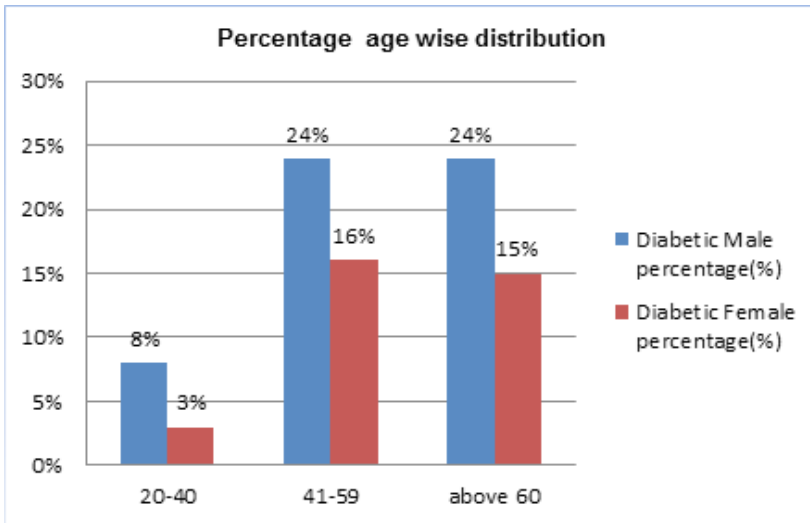

Figure 1: percentage age wise distribution.

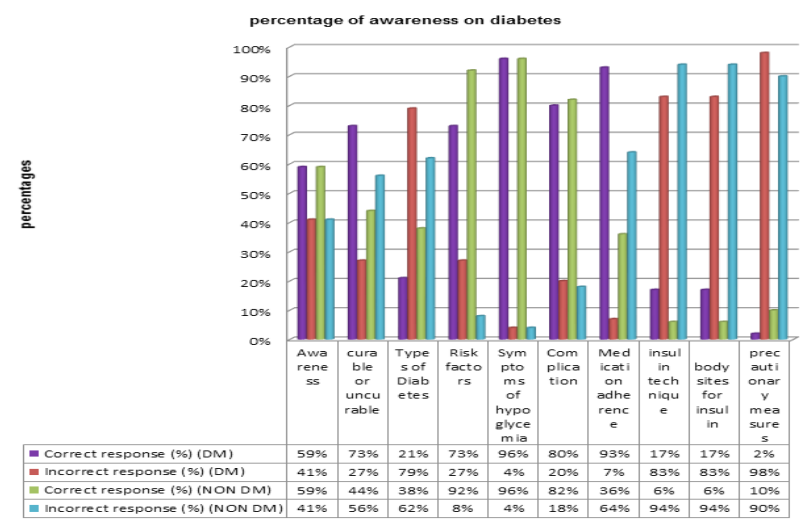

Figure 3: Awareness regarding knowledge of diabetes among study population.

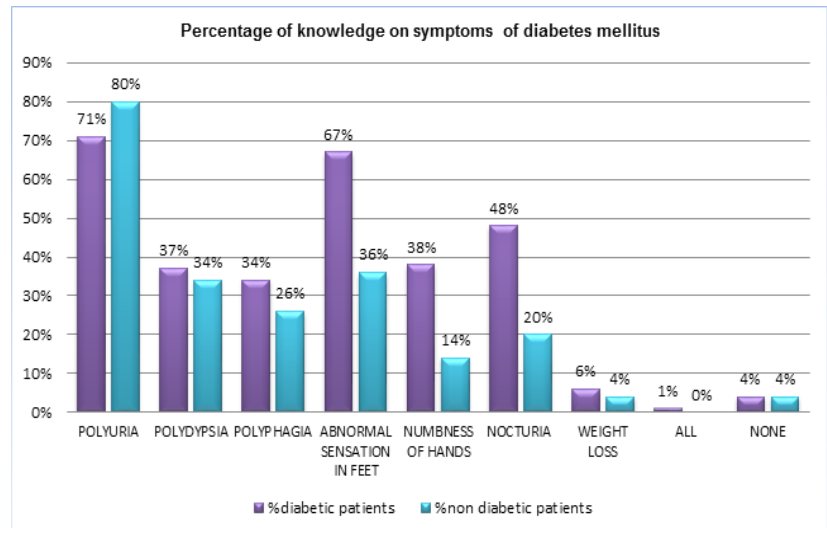

Figure 2: percentage of knowledge on symptoms of diabetes mellitus in diabetic and non-diabetic patients.

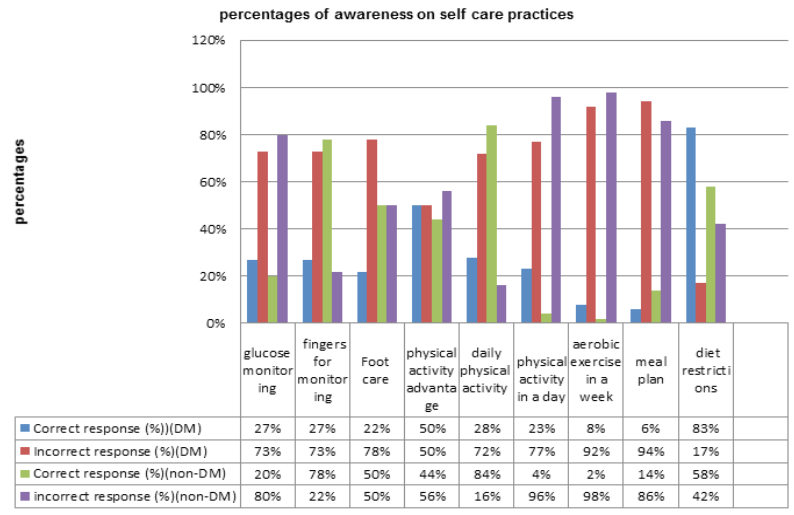

Figure 4: Awareness regarding knowledge on self-care practices among study population.

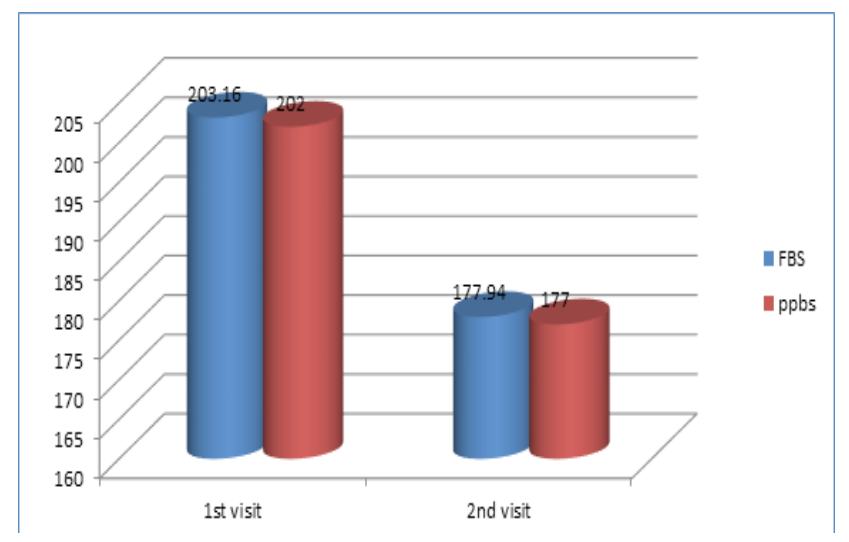

Figure 5: Mean of FBG and PPBG of diabetic patients during their first and second visit.

\section{Knowledge regarding complications of diabetes mellitus}

In this study regarding knowledge and awareness on diabetes Table 6 shows the percentage of knowledge on complications of diabetes for both diabetic and nondiabetic subjects. It shows 4\%diabetic and 4\% non-diabetic was aware on all complications.
Eye Complications: 69\% diabetic patients and 58\% non-diabetic patients knew that DM can affect your eye.

\section{Cardiac complications}

$51 \%$ diabetic and 54\% non-diabetic patients knew that $\mathrm{DM}$ is a risk factor for developing heart diseases.

\section{Kidney complications}


As regards the kidney complication of DM, 59\% diabetic and 54\% non-diabetic were aware that DM is a risk factor for renal diseases.

\section{CNS complications}

$28 \%$ diabetic and 18\% non-diabetic respondents were aware that Diabetes can affect nerves leading to neuropathy while $1 \%$ diabetic and $2 \%$ non-diabetic knew that it can affect the blood vessels. $21 \%$ diabetic and $18 \%$ non-diabetic patients were unaware of diabetes mellitus.

\section{Knowledge regarding symptoms of diabetes mellitus}

Figure 2 shows the comparison between diabetic and non-diabetic patients towards knowledge of symptoms. The results showed that the respondents had a fairly goodunderstanding of the symptomsof diabetes. Early recognition of symptoms may aid inearly detection of the disease, allowing for prompt treatment, the public would not take the symptomslightly and would seek prompt medical attention. The symptoms of Type 2 diabetes are so mild those patients who are fortunate to be diagnosed early do not require long term therapy. It is important to educate the public about the complicationsof diabetes mellitus, sothat they could encourage their diabetic friends or relatives to comply with therapy. This may reduce the burden of diabetes and its complication. Only $1 \%$ diabetic and none of diabetic patients were aware on diabetic symptoms. Majority of Responders (71\% diabetic and 80\% non-diabetic) were aware on Polyuria as a diabetic symptom for where 37\% diabetic and 34\% non-diabetic were aware on polydypsia as a diabetic symptom, $34 \%$ diabetic and $26 \%$ nondiabetic, $67 \%$ diabetic and $36 \%$ non-diabetic, numbness of hands as $38 \%$ diabetic and $14 \%$ non-diabetic, $48 \%$ diabetic and 20\% non-diabetic, $6 \%$ diabetic and 4\% non-diabetic were aware on abnormal sensation of feet, numbness of hands, nocturia weight loss as a symptoms of diabetes mellitus. $4 \%$ diabetic and $4 \%$ non-diabetic participants were unaware of any of the symptoms of diabetes.

\section{Knowledge regarding management of diabetes}

It is essential that diabetic patients should possess good knowledge about their illness in orderto improve their self-management skills and there by prevent complications.Research has found that less frequent selfcare behaviours were evident among particularly high -risk diabetic patients with lower educational levels. For instance, while over $90 \%$ Knew that diabetes can be managed with dietary modification and drugs, only about a third
(Mostly males) of our study participants knew that exercise is an essential component ofdiabetes management. Lifestyle patterns and exercise is known to be very important inmanagement of metabolic disorders like type 2 diabetes mellitus. This study included a set of questions addressing the lifestyle and exercise status of the respondents. Figure 1 shows that $27 \%$ diabetic and $20 \%$ non-diabetic subjects check their glucose levels by the glucometer. $50 \%$ diabetic and $44 \%$ non-diabetic patients are aware on the advantage of physical activity in diabetic patients. $28 \%$ diabetic and $84 \%$ non-diabetic participants gave correct responses to the dailyphysical activity. $72 \%$ diabetic and 16\% non-diabetic gave incorrect response to dailyphysical activity. But only $23 \%$ diabetic and 4\%non-diabeticsubjects with sedentary lifestyle did walking, $8 \%$ diabetic and $2 \%$ non-diabetic subjects did the aerobic exercises for 30 minutes a day for four or more days a week. The general awareness about the metabolic disorders and associated conditions was found to be much lower in the study Population.

In this study Figure 5 shows that the mean of FBG and PPBG values were very high duringtheir first visit and after providing necessary interventions like diet chart, insulin administration technique chart and patient counselling. The mean of FBG and PPBG values has been decreased during their second visit.

By using the study done by (Shahnooshi Javad et al 2014) we gave scores for the each question. (Aware $=2$, partially aware $=1$, unaware $=0$ ) answered by both diabetic and non diabetic patients. The mean score for each section (risk actors, and complications, symptoms and self care practices) was calculated based on the total possible score in each; then it was expressed as mean \pm standard deviation (SD) and then analysis wasdone by using one way ANOVA. The $P$ value $=0.001$ which is highly significant .It shows that diabetic patients had more knowledge than non-diabetic patients .overall study show that in diabetic male patients have good knowledge towards DM etiology and complications than females. But in non-diabetics, females have more knowledge towards risk factors and low knowledge towards DM clinical manifestation than males.

\section{CONCLUSION}

The current study provides a snapshot of the current situation of knowledge and awareness of diabetes mellitus. Present study emphasizes the need for improvement in knowledge and awareness on diabetes mellitus among the diabetic as well as non-diabetic subjects in order to achieve prevention and better control of diabetes risk factors, complications and its management.

Indian Journal of Pharmacy Practice, Vol 10, Issue 1, Jan-Mar, 2017 
After analyzing the scores, it was found that among diabetic patients $46 \%$ had poor knowledge, $45 \%$ had medium knowledge and $9 \%$ had good knowledge regarding diabetes mellitus where as $64 \%$ of non-diabetics had poor knowledge, $34 \%$ of non-diabetics had medium knowledge and $2 \%$.of non-diabetics had good knowledge regarding diabetes mellitus

Out of the total study population, $51 \%$ diabetic male patients, $26 \%$ diabetic female patients where as $42 \%$ non-diabetic male subjects and $52 \%$ non-diabetic female subjects were aware on diabetic risk factors. $61 \%$ diabetic male patients and $35 \%$ diabetic female patients where as $42 \%$ non-diabetic male subjects and $52 \%$ non-diabetic female subjects were aware on diabetic symptoms. $54 \%$ diabetic male patients and 26\% diabetic female patients where as $32 \%$ non-diabetic male subjects and $50 \%$ nondiabetic female subjects were aware on diabetes associated complications. The overall level of awareness in both male and female diabetic and non-diabetic participants was found to be low.

In our present study, we have reviewed the diabetic patients FBS and PPBS values. The mean values of FBS and PPBS of diabetic patients were reduced in their second visit as we provided pharmacist interventions in their first visit.

Regarding knowledge on diabetic self-care practices in our total study population $28 \%$ diabetic patients and $84 \%$ non-diabetic subjects has been performing their daily physical activity. 83\% diabetic patients and 58\% non-diabetic subjects were following their diet restrictions.

There is a big space for raising the educational awareness about diabetes through formal, well organized approaches by healthcare professionals in hospitals, clinics and community based healthcare centres. Because the American Diabetes Association has clearly defined the critical role of diabetes education in quality of diabetic care, diabetes self-management education is a critical element in order to improve patient outcomes. Health care professionals may be additional proactive in disseminates health information about diabetes to the public. Over all, the result of the study indicates, it is essential that the health managers and authorities to take proper steps to increase the awareness among the population regarding causes, symptoms, alternative treatment practices and management of type II diabetes and its complication in order to build our community healthier and prosperous.

\section{ACKNOWLEDGEMENT}

We thank Dr T S Karthik and Dr N Pratyusha for their support.

Indian Journal of Pharmacy Practice, Vol 10, Issue 1, Jan-Mar, 2017

\section{CONFLICT OF INTEREST}

\section{No conflicts of interest}

\section{ABBREVIATION USED}

PCOS: Polycystic ovarian syndrome; GDM: Gestational diabetes mellitus; MODY: Maturity onset disease of young; BMI: Body mass index; DM: Diabetes mellitus; IGT: Impaired glucose tolerance; IFG: Impaired fasting glucose; RBS: Random blood sugar; FBG: Fasting blood glucose; PPBG: Post prondial blood glucose; HbA1c: Glycosylated heamoglobin; ANOVA: Analysis of variance; SD: Standard deviation; CNS: Central nervous system; TV: Television; SC: Sub cutaneous; PO: Per oral; OD: Once daily; BD: Twice daily; TID:Thrice daily; HIV: Human immune deficiency virus; AIDS: Acquired immunodeficiency virus.

\section{REFERENCES}

1. Mafomekong A, Yauba S, Semeeh A, James J. Awareness of diabetes mellitus among diabetic patients in the Gambia: a strong case for health education and promotion. BMC Public Health. 2013;13:1124. http://dx.doi.org/10.1186/14712458-13-1124PMid:24304618 PMCid:PMC3913398.

2. Latifeh A, Reem S. Awareness and knowledge about Diabetes Mellitus among Students at Al - Balqa Applied University: Pakistan Journal of Nutrition. 2012;11:1023-8. http://dx.doi.org/10.3923/pjn.2012.1023.1028.

3. Dr. Purvi M, Dr. Varsha G, Dr. Flagun G, Dr. Krutik B. Knowledge Of Diabetes And Self Care Practices In Chronic Diabetic Patients Attending A Tertiary Care Teaching Hospital In India: NJIRM. 2014;5(2).

4. Shirin J, Farzan S, Ferdous A, Rabiul H, Liaquat A. Awareness regarding risk factors of type 2 diabetes among individuals attending a tertiary-care hospital in Bangladesh- a cross-sectional study.BMC Research Notes. 2014;7:599. http:// dx.doi.org/10.1186/1756-0500-7-599 PMid:25187113 PMCid:PMC4167511.

5. American diabetic association standard guidelines. 2016-09-13.

6. Lin Wee H, Chuen Li S, Kyat Ho H. Public Awareness of Diabetes Mellitus in Singapore: Singapore Medical Journal. 2002;43(3):128- 134.

7. Kanchana D, Primala Krishna S, Rakesh S. Assessment of Diabetes knowledge using questionnaire among people with type 2 Diabetes Mellitus: Asian Journal of Pharmaceutical and Clinical Research. 2015;8(2):254-6.

8. Zia R, Muhammad I, Imran K, Farhat A, Alija B, et al. A survey of awareness regarding Diabetes and its Management among patients with Diabetes in Peshawar, Pakistan. JPMI. 2015;28(4).

9. Muninarayana C, Balachandra G, Hiremath SG, Krishna I, Anil SN. Prevalence and awareness regarding diabetes mellitus in rural Tamaka, Kolar. International Journal of Diabetes in Developing Countries. 2010;30(1):18-21. http://dx.doi. org/10.4103/0973-3930.60005PMid:20431801 PMCid:PMC2859279.

10. Ahmad S, Srivastava A, Goel K, Bansal R, Parashar P, Pant B. Knowledge and awareness regarding diabetes mellitus in urban slum of meerut: Indian Journal of Community Health. 2013;25.

11. Deepa M, Bhansali A, Anjana RM, Pradeepa R, Joshi RS, et al. Knowledge and awareness of diabetes in urban and rural India: The Indian Council of Medical Research India Diabetes Study (Phase I): Indian Council of Medical Research India Diabetes 4: Indian Journal of Endocrinology and Metabolism May-Jun. 2014;18: Issue 3. PMid:24944935 PMCid:PMC4056139

12. Kasinathan D, Nisha RG, Prabhu NM, Manikandan R. Awareness on Type II Diabetes and Its Complication among Sivaganga District Population in Tamilnadu: A Cross Section Survey. Journal of Advanced Scientific Research. 2013;4(1).

13. Sweetha T, Smitha T, Vijay KG. Self care knowledge on diabetes among diabetic patients in Warangal Region: International Journal of Life Science and Pharma Research. 2012;2(2). 
14. Sadikalmahdi H, Mohammed A. Awareness of Diabetic Patients about their Illness and Associated Complications in Ethiopia. Medicine Science. 2013;2(2):512-22.

15. Andreas S, Annika G, Norbert H, Bernhard K, Jörg H, Thomas H. The Diabetes Self-Management Questionnaire (DSMQ): development and evaluation of an instrument to assess diabetes self-care activities associated with glycaemic control: Health and Quality of Life Outcomes. 2013;11: 138.http://dx.doi. org/10.1186/1477-7525-11-138PMid:23937988 PMCid:PMC3751743

16. Abhijit G, Suresh K, Shebang H, Amrita K, Squash P, et al. Awareness towards type 2 Diabetes Mellitus in urban population of Pune, Maharastra, India. International Journal of Pharmaceutical and Bio Science. 2013;4(2):(B) 1070-5.

17. Arnaub P. Assessment of knowledge and awareness towards Diabetes Mellitus in Majuli, Assam of India: A Case study: International Journal of Current Research. 2016;8(7):34910-5.

18. Maral F. Awareness Regarding Diabetes Mellitus and Its' Complications in Type 2 Diabetic Patients: Kinday College Medical Journal March. 2013;9(2):25-8.

19. Anju G, Dharma N, Mesh Raj A. Diabetes related health knowledge, attitude and practice among diabetic patients in Nepal: BMC Endocrine Disorders. 2015;15:25. http://dx.doi.org/10.1186/s12902-015-0021-6PMid:26045031 PMCid:PMC4456997.

20. Jackson I, Maxwell A, Mathew J. Knowledge of self-care among type 2 diabetes patients in two states of Nigeria : Pharmacy Practice. 2014;12(3):404. http:// dx.doi.org/10.4321/S1886-36552014000300001.

21. Deepak M, Deepa R, Shanthirani C, Manjula D, Unwin N, et al. Awareness and Knowledge of Diabetes in Chennai-The Chennai Urban Rural Epidemiology Study. JAPI. 2005;53.

22. Fatma A, Mohamed E, Juma M, Bachar A, Nicolas N, Karin B. Knowledge, Attitude and Practices of Diabetic Patients in the United Arab Emirates: Public Library of Science.

23. Dinesh K, Subish P, Ravi P, Pranaya M. Knowledge, Attitude and Practice about Diabetes among Diabetes Patients in Western Nepal: Rawal Medical Journal. 2008;33(1):8-11.

24. Ashok J, Manias S, Gladius J, Shekhar B. A study to assess awareness regarding Diabetes Mellitus and factors affecting it, in a tertiary care hospital in Kancheepurum District.Healthline. 2013;4(2):2239-337.

25. Fernando L, Poliana R, GiseleA, Carlos K. Knowledge of Diabetes Mellitus: Does Gender Make a Difference?. Osong Public Health Res Perspect. 2014;5(4):199203. http://dx.doi.org/10.1016/j.phrp.2014.06.004PMid:25379370 PMCid:PMC4215000.

26. Maryam A, Seham M. Adolescents' knowledge and awareness of diabetes mellitus in Kuwait: Alexandria Journal of Medicine. 2016;52:61-6.

27. Siham A, Haider A, Mohamed A. Prevalence of diabetes, knowledge and attitude of rural Population towards diabetes and hypoglycaemic event, Sudan 2013: American Journal of Health Research. 2014;2(6):356-60. http://dx.doi. org/10.11648/j.ajhr.20140206.16.

28. Tipaporn P, Shu-Chuen L, Hwee-Lin Wee. A Survey of Knowledge on Diabetes in the Central Region of Thailand: Value in Health. 2009;12. Mohd N, Ahmad F,
Dr. Suraya S. Knowledge and Attitude on Diabetes among Public in Kota Bharu Kelantan, Malaysia: International Journal of Education and Research. 2014;2.

29. Nehad M, Istabraq D, Jyothi V, Husain Y, Umar F. Assessment of Knowledge and Awareness of Diabetic and Non-Diabetic Population towards Diabetes Mellitus in Kaduna, Nigeria. Journal of Advanced Scientific Research. 2012;3(3):46-50.

30. Mashige K, Notshweleka A, Moodley S, Sayed SB, Singh S. An assessment of the level of diabetic patients' knowledge of diabetes mellitus, its complications and management in Durban, South Africa: South African Optometrist. 2008;67(3):95-105.http://dx.doi.org/10.4102/aveh.v67i3.190.

31. Desai R, Parul V, Dhruv P. Effect of awareness of Diabetes on clinical outcomes of Diabetes: An observational study at a private hospital in Gujarat: National Journal of Medical Research. 2012;2(4).

32. Karam P, Samir D, Trupti N, Sameer V. Evaluation of knowledge and self care practices in a Diabetic patients and their role in disease management. National Journal of Community Medicine. 2012;3(1).

33. Minhat SH, Hamedon RT. Understanding towards Diabetes Mellitus among Rural Adult Community in Malaysia: World Journal of Medical Sciences. 2014;11(2):217-21.

34. Salah M, Albaik, M, Yousef Al, Fadil A, Seraj A. Awareness and Knowledge of Diabetes among Al-Wazarat Family Medicine Health Center Attendants. American Journal of Research Communication. 2013;1(12).

35. Yaa O, Christian O, Enoch O, Emmanuel A, Emmanuella N, et al. Knowledge of complications of diabetes mellitus among patients visiting the diabetes clinic at Sampa Government Hospital, Ghana: a descriptive study. Bio Med Central. 2016;16:637.

36. Moodley M, Rambiritch V. An assessment of the level of knowledge about diabetes mellitus among diabetic patients in a primary healthcare setting: South African Family Practice. 2007;49(10):16. http://dx.doi.org/10.1080/2078 6204.2007.10873652.

37. Shahnooshi J, Dr. Shashidhar G, Anita D, Dr. Syed I. Awareness of Diabetes risk factors and complications among Diabetic population at a Tertiary care teaching hospital: World Journal of Pharmacy and Pharmaceutical Sciences. 2014;3(8):549-60

38. Abdelmarouf $\mathrm{H}$, Alzohairy $\mathrm{M}$, Marghoob $\mathrm{H}$. Awareness of diabetes mellitus among Saudi nondiabetic population in Al-Qassim region, Saudi Arabia: Journal of Diabetes and Endocrinology April. 2011;2(2):14-19.

39. Rajenthina S, Nagarjan S. Public awareness of Diabetes mellitus in klang district, Selangor: International Journal of Allied Medical Sciences and Clinical Research. 2014;2(3):186-195.

40. Nelofer K, Kadayam G, Syed I, Jayakumary M. Diabetes Mellitus-Related Knowledge among University Students in Ajman, United Arab Emirates. Sultan Qaboos University Medical Journal. 2012;12(3):306-14.http://dx.doi. org/10.12816/0003144.

41. Carolyne R, Theobald M, Cornelio N. Prevalence and awareness of type 2 diabetes mellitus among adult population in Mwanza city, Tanzania: Tanzania Journal of Health Research. 2014;16(2) 